\title{
COMPARATIVE ANALYSIS OF DIAGNOSTIC APPLICATIONS OF AUTOSCAN TOOLS ON VEHICLE SYSTEMS
}

\author{
A. O. Ezeama ${ }^{1,{ }^{*},}$, P. I. Obe ${ }^{2}$, M. Aniago ${ }^{3}$ and E. O. Ede ${ }^{4}$

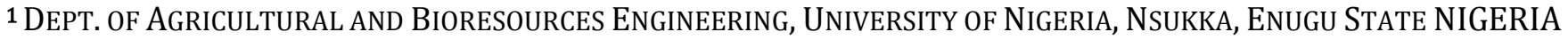

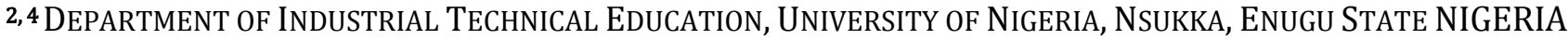

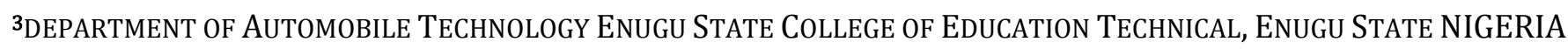 \\ E-mail addresses: ${ }^{1}$ osita.ezeama@unn.edu.ng, ${ }^{2}$ pauline.obe@unn.edu.ng, ${ }^{3}$ aniagomichael@gmail.com, \\ 4edegiwus@yahoo.com
}

\begin{abstract}
The study was carried out in five institutions where motor vehicle mechanics trade is offered as automobile technology which includes, three centers where auto scan tools are used for vehicle repairs and two technical colleges in Enugu state that offer motor vehicle mechanics (MVM) trade. A total of 83 MVM trainers, teachers and instructors comprise the population for the study. Five research questions were raised and three null hypotheses tested at 0.05and 0.01 significance levels guided the study. A structured questionnaire with 3 items questions as checklist, 2 Auto scan tools were used for the study and test carried out on 5 vehicle systems at the 3 centers where Innova $1360 B$ with snap shoot (AST $)_{1}$ was compared with Innova $1360 B$ without snap shoot (AST $)_{2}$ were used for vehicle diagnosis. The instrument was validated by five experts and modifications were made in the instrument according to their recommendations. Analysis of variance (ANOVA) of a two- way classification experiment data with two observations per experimental unit was used for the evaluation. The results revealed that the efficiencies of $A S T_{1 \text { and }} A S T_{2}$ in performing the diagnosis because at $1 \%$ level of significance, the $F$-cal was 0.04 and F-tab was 8.65 but differ in performances on various vehicle systems because at $1 \%$ level of significance, the F-cal was 7.38 and F-tab was 7.01 .
\end{abstract}

Key words: vehicle systems, auto scan - tool, diagnostic application, comparative analysis, evaluation.

\section{INTRODUCTION}

Many Auto Scan tools are available for users and the diagnostic application determines to large extent effectiveness of the tool. Ezeama et al [1] stated that for effective training service delivery in Nigeria, trainers who are abreast of the trends in the theory and practice of motor vehicle mechanics should imbibe continuous professional development as a capacity building exercise [2]. Ogbuanya stated that the dynamism of every changing technology in different field of science and technology requires sound and adequate training of individual in technical education [4]. The Automobile Teacher Education (ATE) planners should promote the use of information and communication technology (ICT) as a tool for enriching the teaching and learning environment of ATE because of current global technological advancement [3]. The advancement of ICT begot modern automotive technology (MAT) as it affects motor vehicle mechanics (MVM).The use of multimedia technologies is seen as a means of qualitative learning by facilitating access to MAT resources and services in ATE
[2].MAT is in the area of Autotronics that is a branch of Mechatronics [2]. However, level of familiarity with MAT will naturally differ among trainers which necessitate the study. The educational infrastructure in Nigeria has been a critical element in supplying a highly qualified workforce to the automotive industry [2]. Hence vehicles of the future will require more sophisticated technology, changing the skills demanded of auto designers, engineers and production workers [1,5,6,]. In automobile education, the use of autotronic simulators and demonstrators as teaching aids with computer softwares, auto scan tools for diagnosis, servicing and maintenance, auto- analyzers, solid work design and canbus hard wares arecan be used for automobile learning and practice [1].Thus, the gap between traditional automotive technology (TAT) and MAT can be easily closed through skill improvement and professional MVM teacher development [2].

The automotive council of Nigeria in its bold effort at capacity building in the repairs and maintenance of new 
generation vehicles had, in collaboration with other stakeholders carried out the following:

- developed and launched a curriculum for teaching automotive mechatronics in the informal sector;

- held critique workshop on the curriculum of automotive mechatronics;

- concluded arrangement for the printing of the curriculum and subsequent launching;

- acquisition of mechatronics diagnostic equipment and tools for training Nigerian auto technicians at specialized centers for teaching of automotive mechatronics [1].

\subsection{Statement of the Problem}

Modern automobile technology (MAT) which is an output of ICT revolves round current technological advancements in motor vehicle mechanics (MVM) resulting in the provision of so many versions, kinds, customized, non-customized or universal auto scan tools for vehicle systems diagnosis. It is obvious that graduates of technical colleges will perform better if they are well trained in their trade areas, as it concern use of different auto scan tools. Most Nigerian youths are unemployed because they lack the necessary skills. Again, some MVM technicians and teachers need skill improvement in MAT because traditional method of vehicle repair will soon put them out of job [1, 2].Vehicle diagnostic equipment (Auto scan tools) is equipment which is used in troubleshooting a vehicle. A scan tool is a great gadget that shows the error code which causes the check engine light to illuminate.

\subsection{Purpose of the Study}

The general objective of the study is to evaluate the effect of diagnostic application of auto scan tools on vehicle systems. Specifically, the study will determine among the tools the most reliable and efficient one.

\section{METHODOLOGY}

\subsection{Research Questions}

The following research questions formed the basis for this research:

(1) How efficient is the Innova 1360B with snap shoot over Innova 1360B without snap shoot in diagnosing automatic braking system defective component faults?

(2) How efficient is the Innova 1360B with snap shoot over Innova 1360B without snap shoot in diagnosing engine system compression faults?

(3) How efficient is the Innova 1360B with snap shoot over Innova 1360B without snap shoot in diagnosing transmission defective component faults?
(4) How efficient is the Innova 1360B with snap shoot over Innova 1360B without snap shoot in diagnosing electrical wiring to a sensor faults?

(5) How efficient is the Innova 1360B with snap shoot over Innova 1360B without snap shoot in diagnosing fuel system faults?

\subsection{Hypotheses}

Three null hypotheses were proposed to be tested.

$\mathrm{Ho}_{1}$ : There is no significant difference between the mean score of activities performed when Innova 1360B with snap shoot and Innova 1360B without snap shoot were used to diagnose vehicle system faults.

$\mathrm{Ho}_{2}$ : There is no significant difference between the mean scores of vehicle systems when Innova 1360B with snap shoot and Innova 1360B without snap shoot were used to diagnose vehicle systems faults.

$\mathrm{Ho}_{3}$ : There is no significant difference between the mean scores of experimental errors when Innova $1360 B$ with snap shoot and Innova 1360B without snap shoot were used to diagnose vehicle systems faults.

\subsection{Research Method}

The data collected were analyzed using mean and Comparative Analysis Index (CAI) to answer the research questions. Analysis of variance (ANOVA) was used to test the hypotheses formulated. Efficiency Need Level (ENL) was determined as follows: the mean (XP) of the performance category was determined for each item; and the efficiency gap (EG) was determined by calculating the correction for the mean, total sum of squares, activities sum of squares, vehicle systems sum of squares, experimental error sum of squares, auto scan tool error sum of squares, vehicle systems mean square, activities mean square, experimental error mean square, and auto scan tool error mean square. The F-calculated for the vehicle systems, activities, the experimental errors and auto scan tools error were calculated as the degree of freedoms, sum of squares, mean squares, and F-values were determined. If EG is zero, it means that efficiency level is not needed for that activity because the level at which the auto scan tools perform the activity is equal to the level at which the efficiency is needed. If EG is negative (-), it means efficiency level is not needed for that activity because the level at which the auto scan tools perform the activity is higher than the level at which the efficiency is needed. If EG is positive $(+)$, it means efficiency level is needed because the level at which the auto scan tools perform the activity is lower than the level at which efficiency is needed [1]. In taking 
decision for performance, any item with mean of 3.50 and above was considered as high performance, 2.50 3.49 was moderate performance while any item with mean of less than 1.50 was considered as very low performance. The null hypotheses were tested at 0.05 and 0.01 levels of significance. The decision for the null hypotheses is that if F-calculated value is less than Fcritical (tabular) value, accept the null hypotheses but if the F-calculated is more than F-critical reject the null hypotheses.

\section{RESULTS AND DISCUSSION}

The data presented in Table 1 showed that mean scores of activities performed had minimum value of 3.53 and maximum value of 5.00 for automatic braking system defective components, had minimum value of 3.20 and maximum value of 4.73 for engine system compression faults, had minimum value of 2.75 and maximum value of 4.31 for transmission system defective components had minimum value of 2.41 and maximum value of 5.00 for electrical wiring to a sensor, and had minimum value of 1.04 and maximum value of 2.91 for fuel system faults. The result of the study shows that auto- scan tools $\left(\mathrm{AST}_{1} \& \mathrm{AST}_{2}\right)$ are reliable and efficient during diagnostic application but differ in performances on various vehicle systems because it is only for fuel system faults during system navigation that had means value of 1.04 and 1.07 which are less than 1.50 that was considered as very low performance.

Table 1: Mean Ratings of comparative effect of diagnostic application (activities) on Motor Vehicle systems studies using auto scan tools ( $A S T_{1}$ and $A S T_{2}$ ).

\begin{tabular}{|c|c|c|c|c|c|c|}
\hline \multirow[t]{3}{*}{$\mathrm{S} / \mathrm{N}$} & \multirow[t]{3}{*}{ Vehicle systems } & \multirow{3}{*}{$\begin{array}{l}\text { Auto } \\
\text { scan } \\
\text { Tool }\end{array}$} & \multicolumn{3}{|c|}{ Activities } & \multirow[t]{3}{*}{ Total } \\
\hline & & & 1 & 2 & 3 & \\
\hline & & & & & & \\
\hline \multirow[t]{3}{*}{1} & Automatic braking system defective components & $\mathrm{AST}_{1}$ & 4.75 & 4.62 & 4.50 & \\
\hline & & $\mathrm{AST}_{2}$ & 4.03 & 5.00 & 3.53 & \\
\hline & Sub-total & & 8.78 & 9.62 & 8.03 & 26.43 \\
\hline \multirow[t]{3}{*}{2} & Engine system compression & $\mathrm{AST}_{1}$ & 3.20 & 3.92 & 3.55 & \\
\hline & & $\mathrm{AST}_{2}$ & 3.21 & 4.73 & 4.48 & \\
\hline & Sub-total & & 6.41 & 8.65 & 8.03 & 23.09 \\
\hline \multirow[t]{3}{*}{3} & Transmission system defective components & $\mathrm{AST}_{1}$ & 5.00 & 5.00 & 3.96 & \\
\hline & & $\mathrm{AST}_{2}$ & 3.45 & 2.41 & 4.61 & \\
\hline & Sub-total & & 8.45 & 7.41 & 8.57 & 24.43 \\
\hline \multirow[t]{3}{*}{4} & Electrical wiring to a sensor & $\mathrm{AST}_{1}$ & 4.18 & 4.31 & 2.75 & \\
\hline & & $\mathrm{AST}_{2}$ & 3.97 & 4.31 & 2.75 & \\
\hline & Sub-total & & 8.15 & 8.62 & 5.50 & 22.27 \\
\hline \multirow[t]{3}{*}{5} & Fuel system faults & $\mathrm{AST}_{1}$ & 2.90 & 1.04 & 2.06 & \\
\hline & & $\mathrm{AST}_{2}$ & 2.90 & 1.07 & 2.91 & \\
\hline & Sub-total & & 5.80 & 2.11 & 4.97 & 12.88 \\
\hline 6 & Grand total & & 35.59 & 36.41 & 35.10 & 107.10 \\
\hline
\end{tabular}

Keys: Five vehicle systems are automatic braking system defective components, engine system compression faults, transmission system defective components, electrical wiring to a sensor, and fuel system faults, AST $T_{1}=$ Innova $1360 B$ with snap shoot and $A S T_{2}=$ Innova $1360 B$ without snap shoot, Activities performed are 1. Run tool programmed 2. Navigate system to access code 3. Perform repairs.

Table 2: Analysis of Variance of Data on Table 1, Showing Sources of Variation, Degree Of Freedom, Sum of Squares, Mean Squares and F-Values (F-calculated \& F-tabular or critical).

\begin{tabular}{|c|c|c|c|c|c|c|}
\hline Source of variance & Df & Ss & Ms & f-cal & $\begin{array}{l}\text { F-Ta } \\
5 \%\end{array}$ & $1 \%$ \\
\hline Vehicle systems (VS) & 4 & 33.7138 & $8.1784 * *$ & 7.38 & 3.84 & 7.01 \\
\hline Activities performed (AP) & 2 & 0.08762 & $0.0438 * *$ & 0.04 & 4.46 & 8.65 \\
\hline Experimental Error (EE) & 8 & 8.8664 & $1.1083 * *$ & 2.48 & 2.64 & 4.00 \\
\hline Sampling (AST) Error & 15 & 6.7132 & 0.4475 & & & \\
\hline Total & 29 & 48.381 & & & & \\
\hline
\end{tabular}

$*=$ significant at $5 \%$ level of probability ; $* *=$ significant at $1 \%$ level of probability 


\subsection{Testing of Hypotheses}

Ho$_{1}$ : There is no significant difference between the mean score of activities performed when Innova 1360B with snap shoot and Innova 1360B without snap shoot were used to diagnose vehicle system faults.

Decision rule: $\mathrm{F}$-cal of 0.04 for activities performed show that there is no significant difference between the efficiencies of $\mathrm{AST}_{1} \& \mathrm{AST}_{2}$ in performing the activities because the F-tab of 4.46 and 8.65 at $5 \%$ and $1 \%$ levels of significances respectively are greater than F-cal thus the null hypotheses is accepted.

$\mathrm{Ho}_{2}$ : There is no significant difference between the mean scores of vehicle systems when Innova 1360B with snap shoot and Innova 1360B without snap shoot were used to diagnose vehicle systems faults.

Decision rule: F-cal of 7.38 for vehicle systems show that there is significant difference between the efficiencies of $\mathrm{AST}_{1} \& \mathrm{AST}_{2}$ in performing the activities because the F-tab of 3.84 and 7.01 at 5\% and $1 \%$ levels of significances respectively are less than F-cal thus the null hypotheses is not accepted.

$\mathrm{Ho}_{3}$ : There is no significant difference between the mean scores of experimental errors when Innova 1360B with snap shoot and Innova 1360B without snap shoot were used to diagnose vehicle systems faults.

Decision rule: F-cal of 2.48 for experimental errors also show that there is no significant difference between the efficiencies of $\mathrm{AST}_{1} \& \mathrm{AST}_{2}$ in performing the activities because the F-tab of 2.68 and 4.00 at 5\% and $1 \%$ levels of significances respectively are greater than F-cal thus the null hypotheses is accepted which indicate that the auto scan tools were certified OK for use by the manufacturers.

\section{RESULTS AND DISCUSSION}

The findings from Tables 1 showed that mean of 3.50 and above was considered as high performance, $2.50-3.49$ was moderate performance while any item with mean of less than 1.50 was considered as very low performance of the scan tools. The result of the study indicated that auto- scan tools $\left(\mathrm{AST}_{1} \& \mathrm{AST}_{2}\right)$ are reliable and efficient during diagnostic application but differ in performances on various vehicle systems because only for fuel system faults during system navigation with means value of 1.04 and 1.07 which are less than 1.50 that was considered as very low performance which was in agreement with findings of Eze [9].Ajagun [7] did recommend that Nigeria should do something to over haul its educational sector or else it would continue to produce "analogue graduates" who cannot fit into the practice and use of modern technology tools. The role of modern automobile technology in advancing knowledge and necessary skills was instrumental in the national policy on education in that for effective functioning in modern world, there is an urgent need to integrate information and communication technologies into Nigeria education system [8].

The findings from Tables 2 showed that null hypotheses which were tested at 0.05 and 0.01 levels of significances on activities performed at $1 \%$ level were so indicative with a maximum distribution value of 8.65 . The decision for the null hypotheses is that if F-calculated value is less than F-critical (tabular) value, accept the null hypotheses but if the F-calculated is more than F-critical reject the null hypotheses. Thus, only for vehicle systems which show that there is significant difference between the efficiencies of $\mathrm{AST}_{1} \& \mathrm{AST}_{2}$ in performing the activities because the F-tab of 3.84 and 7.01 at $5 \%$ and $1 \%$ levels of significances respectively are less than F-cal thus the null hypotheses is not accepted. Also it was noted that performance efficiency of the auto scan tools were not regular as a result of chance factor, sample error, non familiarity of the users with auto scan tools involved and code customization of auto scan tools $[1,2]$.

\section{CONCLUSION}

It was indicative that the auto scan tools were certified $\mathrm{OK}$ for use by the manufacturers. In comparing As the auto scan tools, they were found to be reliable and efficient, but users are to have proper capacity building in the use of the following auto scan tools (AST ${ }_{1} \&$ $\mathrm{AST}_{2}$ ), because it was identified that $\mathrm{AST}_{1}$ will be more useful in diagnosing fuel systems faults. This assertion is affirmed by the findings of the study which agreed on a general note that there is need for MVM teachers to improve in use of modern automobile technology facilities in training of students and carrying out vehicle repairs $[1,2]$.

\section{RECOMMENDATIONS}

Based on the result of the study, the following recommendations were made:

- Motor vehicle mechanics departments should be well equipped with modern automobile technology facilities and competent teachers and users employed to man and use appropriate scan tools during vehicle diagnosis in order to enhance teaching and learning of the trade in our colleges;

- The findings of the study should be made available to policy makers like the automobile council of Nigeria, educational institutions and other cooperate bodies/agencies of education to enable them effect necessary changes in the MVM programme with respect to its theories and practical's. 
- developed and launching of a curriculum for teaching automotive mechatronics in the informal sector;

- held critique workshop on the curriculum of automotive mechatronics;

- concluded arrangement for the printing of the curriculum and subsequent launching;

- the acquisition of mechatronics diagnostic equipment and tools for training Nigerian auto technicians is ongoing at specialized centers for teaching of automotive mechatronics $[1,2,10]$

\section{REFERENCES}

(1) Ezeama, A. 0. Capacity building needs of motor vehicle mechanics teachers in technical colleges in Enugu state. Unpublished B.Sc. (education) project report, Department of Industrial Technical Education, University of Nigeria Nsukka. 2016.

(2) Ezeama, A. O., Obe, P. I. and Ede, E. O. Assessment of Capacity Building Needs among Motor Vehicle Mechanics Trainers for the use of Auto Scan Tools. Nigerian Journal of Technology, Vol.35, No.4, pp. 19. 2016.

(3) http://www.nac.org.ng/achievements.php, retrieved on $2^{\text {nd }}$ July 2015.
(4) Ogbuanya, T. C. The effect of multiple intelligencebased instructional approaches on student's cognitive achievement in Technical College. Electronics Technology 7(1): 1-13. 2010.

(5) What does the computer in a car do?" 01 April 2000. HowStuffWorks.com <http://auto.howstuffworks.com/under-thehood/trends-innovations/question113.htm > 02 July 2015.

(6) www.cd $x$ ete $x$ book.com / safely info vehinfo / information / clear dtc., retrieved on $4^{\text {th }}$ July 2015.

(7) Ajagun, G. A. The Development of ICT Skills through the Nation Computer Education Curriculum for Primary Schools. STAN Proceedings of 44th Annual Conference. 2003.

(8) Federal Republic of Nigeria .National Policy on Education Lagos: Federal Government Press. 2004.

(9) Eze, S. I. Effect of Using Computer as Tutor and Tool on Students' Achievement and Retention in Quadratic Equation in Enugu State. Unpublished Ph.D. thesis: University of Nigeria Nsukka. 2011.

(10) http:minstructable s.com/id/using-a-scan-too-tDiagnose your car/All steps retrieved on $2^{\text {nd }}$ July 2015. 